\title{
Following the red thread of information in information literacy research: Recovering local workplace knowledge through interview to the double
}

\section{Introduction}

Information literacy is a practice that connects us with information and knowledge about other practices that shape our setting and context. It manifests explicitly in our engagement with texts, and implicitly when we engage with others. When we draw on our embodied experiences to help shape solutions to problems, we are engaging with ways of knowing that contribute to our information literacy practice.

However, information literacy practice researchers are faced with a challenge when they move beyond the domain of text. This is especially true when examining the social and embodied aspects of information literacy practice in action. As the practice of information literacy is central to both formal and informal learning, then the ability to view it holistically and represent it as it is performed within context becomes an important task for information literacy researchers. How to understand its arrangements in education, workplace or everyday settings is the focus of this article.

Seeing information literacy in the workplace or in everyday spaces is difficult, because a practice is not a single unit or object, but composed of a set of activities that work together to produce a project or meet a specific end (Schatzki, 2002). This point is particularly salient in the workplace, where the information landscape and the specific knoweldges that shape it are complex, messy and distributed in a complex ecology of interconnections. The complexity of the workplace means that ways of knowing about performance and practice of work require people to draw from the material, semantic, embodied and social spaces that structure the information landscape of the workplace, and in doing so, to connect with the normative and non normative sources of information that comprise those spaces (Lloyd, 2010).

The emphasis of information literacy research is often focused towards capturing and describing activities related to normative aspects of information literacy. There is less emphasis on capturing the non-normative aspects that are related to the knowledges that are embodied and embedded as part of everyday performance, which make an important contribution to the performances of work.

Normative information sources reflect the epistemic/institutional view through which practice is operationalized and corresponds to the rules, regulations, and prescribed ways of knowing. This view is often represented as an outsider view (Gherardi, 2013), and because of its explicit nature is easily accessed by researchers. 
Non-normative information sources are trickier to access and capture because they reflect the insider, or internal view that represents the social and embodied aspects that shape performance and ways of knowing. Insider views are founded on ways of knowing that are articulated through collective action and the development of intersubjective agreement about where knowledge resides and what knowledges are important (Gherardi, 2001; Lloyd, 2006).

Non-normative aspects of information literacy reflect the situated and the social; these emerge through the shared understandings of people about ways of knowing how the information landscapes of a setting are constructed, and how information is negotiated and navigated within them (Lloyd 2010). This way of knowing is part of the local knowledge of the setting and embedded in the everyday routine of people within it. Local knowledge is contingent and called upon at the moment of practice (Bonner \& Lloyd, 2011), and is a source of expertise. It provides a point of view that can only come from being situated i.e. being there at the same time, in the same place. It is accessed through routine performances and is highly nuanced (Yanow, 2004). Local knowledge about what activities and skills will enable participants to connect and engage with an information landscape develops in interactions with other people who are involved in the same programs, operations or material objects.

\section{Problem Statement}

The competent performance of work entails the capacity to draw from a wide range of social, material, and embodied knowledges. This requires that workers develop their ability to know and navigate the information landscapes of work. From a research perspective, recovering explicit knowledge about the normative aspects of information literacy practice is reasonably achievable. Recovering and capturing local insider knowledge about the activities that connect workers to local knowledge represents a different kind of challenge.

Making local knowledge visible presents a methodological challenge for the design of information literacy research, because it is embedded in everyday routine and often represented as nonverbal or nuanced knowing, and derived from practical reasoning (Yarrow, 2004). From a sociocultural perspective, this means capturing information literacy practice that is embodied in the everyday practices of people in order to gain access to information that will inform the development of competence in the workplace.

A way forward is to follow the 'red thread of information' (Bates, 1999, p.1048) to identify how information literacy is constructed as ongoing social practice, and in doing so, employ a wider range of techniques that may elicit local knowledges related to socially situated practice. The metaphor of the 'red thread' highlights the role of information as it weaves through and within the workplace, binding and connecting people who are collocated and connected by a shared understanding of the performances of work.

The value of this work lies in the introduction of a data collection technique known as Interview To The Double (ITTD) as one potential solution to this issue in information literacy practice research. The 
strength of this technique rests upon its ability to capture information that is only called upon at the moment of practice, and is central to the performance of work.

\section{Locating information practice}

The concept of information practice draws from the field of practice research (Bourdieu, 1977; Giddens, 1984; Lave \& Wenger, 1991; Schatzki, 2002). The general, practice has been described as performative, situational and social, emphasizing relationships and interaction between people, within communities and in relation to material objects (Gherardi, 2001; Lloyd 2010; Orlikowski, 2002; Østerlund \& Carlile, 2005; Schatzki, 2002). Exploring a practice provides insight into the social, material, and economic dimensions of the setting and the 'social, casual, intentional and prefiguring relations' (Cox, 2012, p. 2) that exist through the practice as a social site (Schatzki, 2002). This suggests that meaning and intelligibility are inherent within practice (Schatzki, 1996) and represented by a range of explicit and tacit knowledges that combine together to operationalize work and influence positionality. Practice approaches draw from the concept of situated action, to understand how activities are situated in a particular space and in relation to particular objects or performances (Suchman, 1987; Gherardi, 2013). This approach attempts to understand the 'texture or web of practices' that connect an organization internally and externally (Gherardi, 2013) enabling organizations to reduce uncertainty by ordering 'the flow of organizational relations' (Gherardi, 2013, p. 2). Framed through this perspective, information literacy can therefore be understood as a practice that connects other practices by facilitating a flow of information, through a range of activities and skills, which connect together to form a way of knowing (Lloyd, 2010).

The shaping of information literacy practice occurs through the practice architectures (Kemmis \& Grootenboer, 2008) that shape a setting. This theory highlights what practices are made up of- namely sayings, doings (Schatzki, 2002) and relatings (Kemmis \& Grootenboer, 2008). Sayings (what is said) doings (how is it done) and relatings (how it is referenced) are entwined in the settings projects which in turn reflect the various traditions/histories or ways of knowing that are valued and legitimized. Practice architectures create the conditions that enable or constrain the way a practice, such as information literacy will be performed or conducted. These conditions emerge through the culturaldiscursive, material-economic and social-political arrangements which compose a site (BrennanKemmis, Ahern \& Middleton, 2012; Kemmis \& Grootenboer, 2008; Lloyd, 2010). The theory of practice architecture can help us to inform research into information literacy practice by focusing on the way information and information sources are situated within a landscape, and the dialogic and cultural activities that people routinely use to inform their working practice.

\section{Information practice}

As information literacy is viewed as a practice, and as an example of information practice, it is also prudent to connect the concept of practice with the work that has been undertaken in the areas of information practice. The concept of information practice is a central issue for researchers with an 
interest in understanding how and why social conditions enable or contest information behaviors related to information creation, access, dissemination and use within a given setting

As a research concept in Information Studies, information practice has been explored and also described by a number of researchers (Cox, 2012; Lloyd, 2010; McKenzie 2002; Savolainen, 2008, Talja 2005). These researchers have drawn from a range of sociocultural/theoretical approaches that situate information practice as a social practice that is constituted within a setting and reproduced in the ongoing routine actions of people as they interact with each other. Within the information practice research field there is some discussion of what constitute an information practice. The approach has been characterized by Talja (2005, p 123) as 'a more sociologically and contextually oriented line of research' where the focus is on the social and dialogic construction that underpins information seeking and use as these activities are operationalised within a given setting, and according to the social conditions that inherently shape the setting.

Savolainen (2008, p. 2) describes information practice as a 'set of socially and culturally established ways to identify, see, use and share the information available in various sources such as television, newspaper and the Internet'. From this perspective an information practice approach acknowledges the social and cultural conditions that influence the production of information and information behavior, but continues to confine the practice within a cognitive paradigm

Lloyd (2010; 2012) views practices from a broader perspective, that encompasses social, embodied and relational aspects. From this perspective practices are composed of a constellation of activities (e.g. information sharing, information seeking and searching, collecting) that together reflect the inherent cohesive social order, arrangements and knowledge domains of a particular site. These aspects influence ways of knowing how information is produced, reproduced, circulated, accessed and used, and entwine together in a network, which forms a social site that promotes and legitimizes certain types of social practices, knowledge and activities over others.

Lloyd views an information practice as:

an array of information related activities and skills, constituted, justified and organized through the arrangements of a social site, and mediated socially and materially with the aim of producing shared understanding and mutual agreement about ways of knowing, and recognizing how performance is enacted, enabled and constrained in collective situated action. (Lloyd, 2011, p. 285)

Talja and Hansen (2006) identify information practices as ' practices of information seeking, retrieval, filtering and synthesis (2006, p. 113). Lloyd (2010) views these elements as activities rather than practices in themselves. While differences between approaches to information practice are still emerging and in debate, the common elements within all approaches are a focus on people as they connect with information in order to participate in the practices related to their participation in the workplace and with the ongoing performance of their work. 


\section{Exploring the practice of information literacy}

Information literacy represents an example of an information practice that is influenced by socialdiscursive, material-economic and social-political arrangements that prefigured it within a setting (Lloyd 2010). As a practice it therefore has relational, material and embodied dimensions that connects people with explicit and implicit knowledges, and enacts them into the practices of a particular setting (Lloyd, 2010). Nurses, for example, will draw from their epistemic knowledge base using a range of searching techniques that will connect them to specific types of nursing/medical literature which they then use to inform their practice. Similarly, on the ward they develop ways of connecting with information that specifically informs their practice. The ability to successfully cannulate a dialysis patient may require local knowledge that can only be gained by observing another person and listening to the narrative that may also accompany this demonstration (Bonner \& Lloyd, 2011). In effect, they learn 'what works', what activities (formal or informal) connect them with information specific to their practice, and where to find the information specific to their practice. Therefore, when we explore information literacy in a setting, we are exploring the practice as a social site, identifying the activities and skills that compose the practice, and attempting to identify the practice architectures that prefigure and legitimize knowledge and ways of knowing within a specific setting.

Information literacy is therefore represented as a constellation of purposeful activities (i.e. information sharing, information seeking, collecting, observing, narrating etc.) that together reflect the inherent cohesive social order, arrangements and knowledge domains of a particular site and represented through ways of doing, saying and relatings (Kemmis \& Grootenboer, 2008; Schatzki 2002). These aspects influence ways of knowing how information is produced, reproduced, circulated, accessed and used, and entwine together in a network that forms a social site that promotes and legitimizes certain types of social practices, knowledge and activities over others.

\section{Following the red thread of information literacy practice.}

To follow information literacy as it is practiced means that researchers must follow information as it is encountered, created and circulated within a setting. This necessitates that normative and nonnormative aspects of the practice must be made visible. Therefore, researchers must develop techniques that enable them to recover the explicit aspects of the practice as well as aspects that are embedded in local knowledge related to 'how things are done'.

The metaphor of the 'red thread' (Bates, 1999, p.1048) is used as a conceptual tool to draw attention to information and information related relationships and activities that facilitate enactment in a social setting (e.g. people become a nurse, a doctor, a teacher, a musician or a student) by engaging with the knowledges and information practices of the setting. The red thread represents information that acts as an invisible link that ties people together in a social tapestry (Bates, 1999). In studies of information literacy practice, we follow the red thread of information to understand the social conditions that enable and constrain people's engagement with information, and the development of information related 
activities that flow through the social tapestry connecting other practices together in a social site.

Taking up this metaphor Bates describes the 'red thread' in relation to the research of information:

In comparison to other social and behavioral science fields, we are always looking for the red thread of information in the social texture of people's lives. When we study people we do so with the purpose of understanding information creating, seeking and use (Bates, 1999,

p.1048)

While some activities related to information literacy practice are visible and observable, some may also be invisible because they are not only tied to explicit forms of knowledge, but also to local knowledge where they are tied to expertise that comes from being situated. To recover local knowledge about information literacy practice that may only become explicit when recalling the moment of practice requires that researchers attend to the activities of the practice as it happens.

\section{Recovering local knowledges in workplace: Interview to the double}

Workplaces are composed of a range of knowledges that describe structure and content of a setting and each workplace requires different ways of knowing. Formal propositional knowledge will be represented in epistemic modality and codified in text. Other forms of knowledge (procedural, or contingent) are not easily expressed in written form, thus relying on social interaction for distribution (Blackler, 1995; Lloyd, 2006), because they are local and nuanced in ways that can only be understood in the setting.

Canagarajah (2002, p. 244) suggests that 'local knowledge is context bound, community specific and non-systematic because it is generated from the ground up through social practice in everyday life'. It also represents a significance source of information within a workplace. However, identifying these sources and the activities that may connect workers with local knowledge is problematic because it tends to be embedded within everyday routines specifically related to the practices of the setting. According to Canagarajah (2002) when understood from social perspective, 'local knowledge contrasts with official knowledges that inform policy and procedures because people generally develop extrainstitutional (or vernacular) discourses in their own terms (Canagarajah, 2002, p. 243). From a professional perspective local knowledge is nuanced by the setting, and reflects ways of doing things or knowing things or contingent strategies (tricks of the trade) that are not part of the epistemic narrative (rules, regulations etc.) that shapes workplace practice (Canagarjah, 2002, p. 243). Local knowledge can therefore be viewed as non-normative.

Recovering local knowledges represents a particular challenge for information literacy researchers, who must focus on the situated activity of people as they connect and engage with information sources and agreed upon ways of knowing (sociocultural and sociomaterial) in constructing an understanding of the practice. Following the 'red thread' in information literacy research, suggests that researchers focus on; locating and then describing how people construct knowledge about their information landscapes; identifying the type of information sources that are agreed upon and, its importance in practices; how access and use position the worker; and, finally, understanding the range of activities 
normative and non normative activities that characterize information activity within a given setting. In effect, the focus is on the ongoing relations of the practitioner community and on the sayings, doings and relatings of the practice. While traditional qualitative techniques such as interviewing will produce this kind data, there is always the risk of researcher bias in the reporting of description. There is also the risk that local knowledge may be missed because it becomes 'invisible' outside the setting. In organizational studies, a projective technique known as Interview to the Double (Gherardi 2013; Nicolini, 2009) has been employed to access more emic descriptions of practice, thus reducing bias. This technique has potential to be added to the methodological toolbox of information studies researchers.

\section{Interview To The Double}

Originally rooted in the Marxist tradition, this emancipatory technique was used to 'recover and legitimize the local knowledge that workers learned on the job and passed on to novices (Nicolini 2009, p. 197). This projective technique has been employed in actor network studies, in the context of adult training, and as a way to elicit knowledge located in 'micro-decisions(Gherardi 2013, p. 162). In applying the technique, participants are asked to imagine that they will be replaced by a double in their job. To prepare the double, participants must provide detailed instructions to ensure that the switch to the double is not revealed. (Nicolini, 2009, p. 196).

When applied to information practice studies, this technique has the potential to allow participants the opportunity to articulate and (re) present their awareness and understanding of information and information literacy practice along with the activities and skills that compose the practice (Nicolini, 2009), from the ground up. It does so by allowing the participant to reflect on what is important to them, and provides furnishes an opportunity to draw from local knowledges, that may be not be foregrounded in researcher led interviews. From this perspective the technique has merit because it allows practitioners to turn into observers of their practice, producing a description of use that is emically derived, capturing the experience of information from the perspective of the user. In discussing the use of this technique, Gherardi (2013) has suggested that 'Whilst an inquiry from outside focuses the researcher's attention on 'doing', an inquiry from inside focuses on 'knowing' as a collective doing' (p.162).

ITTD differs from other techniques, such as think aloud, where subjects are encouraged to explicate their deliberations in the process of undertaking a task. The technique also differs from standard ethnographic interview techniques that are based on an interactional negotiation of meaning (and the traces these leave) between the researcher and participant. Nicolini, (2009) suggests that in essence, think aloud technique produce a transcript of data that can then be merged into a range of categories that reveal the decision making process. Where ITTD differs is based on the 'premise that all research, interviews or other, necessarily generate 'data' whose nature cannot be separated from their process of interpretation' (Nicolini, 2009, p. 200). The interaction that is set up is not between the researcher and the participant, but between the participant and the double. Therefore, ITTD is a situated interaction 
that has the possibility of being imbued with specific acknowledgement of the local and authentic knowledges held by the participant.

When used with observational techniques or emerging reporting techniques such as photo voice, ITTD allows researchers to understand the 'situated activity' (Nicolini, 2009, p. 196). From an information practice perspective, ITTD allows the researcher insight into what information and ways of knowing are important in relation to situated activity and in the context in which the practice takes place.

When information literacy practice is explored, we are in fact examining two practices simultaneously our own epistemic practice and the subject of our concern (Nicolini 2009, p.197). As researchers we must be aware of positions, assumptions (about what constitutes information and knowledge) and how social conditions structure our understanding. Drawing from Schatzki, Nicolini (2009) argues that 'practice always needs to be bought to the fore; it needs to be made visible, articulated, and turned into an epistemic object in order to enter the discourse. Practice can never be apprehended in an unmediated way and the notion that practice is 'just what people do' is a return to a naïve form of empiricism.' (2009, p. 196). These thoughts resonate with the challenges faced by information literacy researchers, namely how to make information literacy practice which connects people with social, corporeal and epistemic modalities visible and the to (re)present this practice in ways that reflect the normative and non-normative information sources that constitute the information landscape.

\section{Application of the technique: Informing safety at work: Study context}

The ITTD technique was included in the pilot of a study of aged care workers. This study (which will be reported at a later date) focused on understanding how aged care workers informed their understanding of safety and safe working practices. The study aimed to trial the interview schedule and ITTD question.

The aged care setting was complex with different levels of aged care workers and hierarchical work structures. Qualified nurses directed and oversaw the work of vocationally trained assistants in-nursing. Common to each of these worker categories is a recognition of local knowledges that are intersubjectively understood, which act to locate the workers within particular shared information environments, and specific information landscapes related to their practice. Local knowledge is shared across the information environment because it impacts on the work of each group. Within each group a further hierarchical structure is also evident, but this is based on experience in the job rather than the recognition of formal qualification.

While most of the pilot study followed a traditional qualitative process employing face-to-face semistructured interviews, a second aim was to pilot the ITTD technique to understand the strengths and limitations of the technique in relation to its ability to capture the local knowledge which is nuanced and often only available at the moment of practice. The ITTD question was asked at the conclusion of the interview schedule. The decision to ask the ITTD question at the end of the interview was to allow participants time to become comfortable with the interview process and to enter a reflective space. 
The pilot sampled 10 participants who were asked the ITTD question at the end of the 60 minute interview schedule. The responses to the ITTD question varied between 10 and 20 minutes. Following the ITTD technique described by Gherardi (2013) and Nicolini (2009), participants were asked to imagine that they are training a 'double' to take their place the next day. Participants were advised that the double must not be detected by others as an imposter, so the participant must provide the double with as much information as possible to achieve this aim.

This scenario was described for the participants and a single question was asked:

'Now, I want you to imagine that you are teaching this double the things they will need to know about safety and safe working practice in order to be you. You also need to tell the double where to find information that will help them to remain safe - and not to arouse suspicion. What will you tell them?'

The intention of this technique is allow participants to produce a soliloquy that will create a 'multifaceted representation of practice' (Nicolini, 2009, p.196.). From an information literacy perspective the focus was on identifying the types of information that the participants thought was personally important to their work performance, allowing them to draw from their own experiences and understanding of how that information was created, circulated and disseminated, and to reflect on how information is used within the information landscape. This is a particularly useful technique for information practice studies as it allows the complexity of the practice to unfold from an emic perspective and also recognizes that information literacy is intricate and multifaceted. The intention in asking this question at the end of the interview is to create a reflexive space where by participants now familiar with the flow of the interviews are given 'space' to reflect on their practices and in the case of this study, their information literacy practice. As projective technique (Gherardi, 2013), ITTD aims to give researchers access to the way in which participants view their world and the types of information, knowledge and information related activities that they see as being important; this includes the local knowledges and ways of knowing that are situated within the setting and may only be available at the moment of practice. By encouraging an insider perspective, it was hoped to capture some common elements of local knowledge that enabled information literacy to be enacted by this group of participants.

Unlike conventional interviewing, there are few prompts used in ITTD, enabling the participants to explore the area under investigation in their own way, in as much or as little detail as they wish, identifying what is important to them, and allowing them to draw from their 'know-how' knowledge, rather the being directed towards themes considered important to the researcher (Nicolini, 2009).

\section{Findings from the ITTD technique}

The data from the ITTD technique were coded separately from the main pilot interview questions. This was done to highlight the level of participant reflection this technique can provide in relation to accessing local knowledges. A grounded approach (Charmaz, 2006) was employed to code the ITTD responses, using a constant comparison method that aims at achieving saturation within the categories 
(Charmaz, 2006). What is emphasized with the use of this technique are activities that often become invisible because they have become part of the routine and embedded in everyday practice.

The analysis of ITTD question highlights that for this group of participants, safety was informed by connecting with other people through the sayings and doings related to safety and through spatial awareness. In advising the doubles, participants were required to draw from knowledge that may not be specifically explicated but are relevant to their local situation and thus form part of the local knowledge of the workplace. These knowledges are now briefly discussed, with direct quotes from participants italicized.

\section{Getting 'in the know'}

The most common suggestion given to the 'double' was to get 'in the know' by talking to other people and carefully observing what other members were doing as part of their work practice. Getting in the know is viewed as a state that once achieved situates and positions workers in this setting and allows them to work safely and in consort with other aged care workers. A significant element of getting in the know was the enactment of safety routines and having this knowledge was considered as critical to staff because it impacted on the safety of residents. Social sources were considered central to the doubles becoming situated. Participants advised their 'double' to quickly develop knowledge of other people and who to trust, and to map this knowledge closely against other people's experiences. Participants reminded the double that routine activities were a significant source of information and encouraged the double to engage in activities such as talking to other workers. The double was routinely advised and encouraged to seek out experienced workers for advice. Talking and listening was viewed as valuable activities. While residents, who are experts in the residential space, were seen as a valuable source of local knowledge about the setting that was highly valued among all participants. A sentiment commonly expressed was "If you are unsure of something, ask someone, use common sense, and always play it safe".

\section{Doing by the book}

Knowing what information sources were important to daily work was a common theme of advice to the 'doubles' who were routinely advised to develop an awareness of print based sources (rules, regulations, handbooks, policy and care plans) which act as key sources of discursive knowledge that could be referred to in times of doubt or uncertainty. Print resources were viewed by participants as the legitimate source about rules and regulations and would act as a primary tool that would enable the double to engage with the discourse of the setting and discourses related to safety. This was considered important because of the highly litigious nature of aged care provision.

Doubles were advised that doing it by the book would demonstrate familiarity with safety requirement. Information about care plans for each patient were kept behind the door and doubles were advised to check this location, this advice represents an example of local knowledge. Doubles were urged to ensure they were compliant and this was viewed by participants as an important way of keeping the double safe and working within the safety of regulatory authorities. In describing what they would tell 
their double, aged care workers identified a wide range of compliance resources that create their awareness of safety and safe working practices. These information sources help to focus the attention of aged care workers towards an institutionalized construct of safety and safe working practices. In addition to epistemic sources, doubles are also alerted to the importance of sharing information about everyday routine events and this can be summed up as "Talk to your staff, to your RN, you talk to the residents. Another participant reiterated this in another way by suggesting "I would tell them to be aware of people and who to go to".

\section{Knowing limitations}

Participants cautioned their 'doubles' to be aware of the physical space and material objects that occupy particular settings and the role objects played in the performance of work. Doubles were advised to become familiar with how equipment worked and what the manual handing regulations were. Doubles were also advised to be aware of bodies: residents' bodies and their own body, as they occupy the space. They were advised to be aware of the limitations, of potentials sources of risk and danger to themselves and the residents in their care. One participant summarized this awareness as "being aware of their own bodies, their own safety; what the wet floor sign means". Corporeal awareness extends not only to residents' bodies, but also to participants' bodies summed up in the following way" know your limitations, because if you go over your limitations, then you can get into trouble”.

\section{Connecting with local knowledge through sayings, doings and relatings: Working with ITTD}

In working with this technique, information literacy researchers focus on locating and drawing out the 'red threads', to understand what knowledges are important and how information literacy practice is operationalized. The threads weave through the social sites' practice architectures of sayings, doings and relating (Kemmis \& Grootenboer, 2008; Schatzki, 2002). The sayings represent the shared language of the workplace discourse, and are present in sanctioned and legitimized knowledges that shape the practice of safety. These sayings may not be revealed in situations that are interviewer driven rather than participant, because they are part of local knowledge and routine practice. In describing what they would tell their double, aged care workers identified a wide range of compliance resources that create their awareness of safety and safe working practices. These information sources help to focus the attention of aged care workers towards an institutionalized construct of safety and safe working practices that are considered important to workers. The sources were important to all workers as a team and form part of the collective memory that helps to bind the team together.

While the participants describe the importance of epistemic knowledge, the ITTD also uncovers a range of contingent strategies that are nuanced within the setting (e.g. checking behinds doors, being aware of resident bodies as source of risk, knowing who to talk to /who not to talk to; being aware of limitations; knowing the rules). These strategies form part of daily routine and may only be present at the moment of practice or recalled when guidance is required. Drawing these activities out through this projective technique enables researchers to grasp local knowledge that is embodied, context bound, 
non-systematic, and grounded in the realities of practice. It therefore represents an insider view of the way information literacy occurs in everyday life.

Doings reflect embodied experiences of practice, and connected the aged care worker with information associated with the corporeal aspects of aged care work and material affordances relate to the layout of workplaces, sites, and equipment. In this space, safety is situated and enacted through routine performance and observation of others. The contingent nature of local knowledge can be drawn out as people actively reference their advice to the doubles against their own experience e.g. being aware of bodies and knowing limitations.

Relatings referred to the intersubjective space that workers occupy as they work in consort with each other. This space is negotiated through the information sharing and listening activities of workers. By employing an ITTD technique to information practice based studies, researchers are also able to provide a level ground for all participants from which to articulate their responses, which may not necessarily be the case with focused research questions. In this respect, a benefit in coding the responses will be the ability not only to determine the specific aspects of local knowledge that reflect the participants' role and responsibilities (e.g. as novice or expert), but also reveals the idiosyncratic knowledges that are specific to the participant's own practice, allowing for comparison. The data this produces can then be compared against the broader canvass of research data.

\section{The strengths and weakness of the ITTD technique}

The pilot study demonstrates that there were strengths and weaknesses with the technique that need to be taken into account.

\section{Strengths}

It was determined that this technique has potential for researchers as it allows the complexity of the practice to unfold from an emic perspective and has the potential to therefore recover the local knowledges that are important to the participants. From an information literacy perspective, this approach has the potential to recover the local knowledge related to information access and use, which are embedded in the daily routines of everyday practice.

When employed in conjunction with other qualitative data collection techniques, the ITTD technique has the ability to access and recover local knowledges that may not be accessible through researcher and participant interaction, because they are routine and embedded in other practices. This is primarily due to the technique requiring participants to produce a narrative based on their own reflective understanding of their practice. This approach allows participants to bring to the researcher's attention, and to interpretation and analysis, small things about their information literacy practice in relation to their work that may be forgotten in grand narratives about how work happens. These things may reflect the normative and moral textures of the local practice, (Nicolini, 2009) which influence the power dynamics around information provision. For example, in the present study, the importance of epistemic information (located in the rules, regulations and care plans) was emphasized as important knowledge 
because it enabled workers and residents to remain safe and within the boundaries of what was collectively agreed upon as good practice

As an addition to the suite of techniques for information practice studies, the ITTD technique provides a unique and empowering approach to capturing local knowledges that are the foundation of know-how within workplaces. These knowledges often fall outside the realm of the researcher's expertise of a particular practice or field, because they are situated, and 'generated ground up through social practice in everyday life' (Canagarajah, 2002, p. 244) and often only occur at the moment of practice. They may subsequently remain largely unrecognized, if not explicated by participants in response to research questions, and leave critical threads of information that could help to enrich the narratives and representation of participants' experiences unexplored.

\section{Limitations}

Having indicated the possibilities of the ITTD, it is also important to indicate that there were some limitations, particularly as this was the first time this technique has been trialed in information literacy research. Firstly, it is important for researchers to recognize that projected interviews can often be intimidating for participants because it calls upon them to demonstrate their expertise or knowledge through their advice to the double. Consequently it is important to ensure that rapport is first developed prior to data collection, while at the same time recognizing that good rapport may not encourage participants' projection. Secondly, the technique allows participants to produce a largely uninterrupted soliloquy. Participants will therefore report what is important to them rather than to the researcher (Nicolini, 2009 p. 199). Finally, the technique needs to be included in a suite of techniques rather than considered as single data collection tool. A future study is planned to explore the use of this method in association with the photo-voice technique.

However, despite the limitations, it was determined that this is a particularly useful technique for information literacy studies as it allows the complexity of information practice to unfold from an emic perspective and also recognizes that information practice is intricate and multifaceted.

\section{Conclusion}

The methodological toolbox of information literacy practice studies requires additional tools and theoretical concepts to frame the complexity of people-in-practice. The theoretical framework provided by practice based concepts and the unusual data collection technique of interview to the double, which was trialed in this research, provide a way of understanding the constant and complex interplay between various modalities of information which are significant in the information landscape of aged care work, and inform the performances and practices of work. Workplace knowledge is multimodal and socially complex and to connect with these knowledges workers must follow and gather threads of information in order to construct a sense of their workplace and the knowledges required to operationalize their working practice. These threads tie people to place, others, and the material artifacts of their practice 


\section{References}

Bates, M.J. (1999). The invisible substrate of information science. Journal of the American Society for Information Science, 50(12), 1043-1050.

Blackler, F. (1995). Knowledge, knowledge work and organizations: An overview and interpretation. Organization Studies, 16(6), 1021-1046.

Bonner, A., \& Lloyd, A. (2011). What information counts at the moment of practice? Information practices of renal nurses. Journal of Advanced Nursing, 67(6), 1213-1221.

Bourdieu, P. (1977). Outline of a theory of practice. Trans Richard Nice, Cambridge, NY: Cambridge University Press.

Brennan -Kemmis, R, Ahern, S., \& Middleton, D. (2012). Promises and expectations between apprentices, trainees and their employers. Australian Vocational Education and Training Research Association (Avetra) 15 thAnnual Conference The value and voice of VET research for individuals, industry, community and the nation, Thursday, 12 - Friday, 13 April 2012 Rydges Capital Hill, ACT. Retrieved from http://avetra.org.au/annual-conference/conference-2012-papers Charmaz, K. (2006). Constructing grounded theory: A practical guide through qualitative analysis, London, UK: Sage Publications.

Cox, A. (2012). An exploration of the practice approach and its place in information science. Journal of Information Science, 38 (2), 176-188.

Canagarajah, S. (2002). Reconstructing local knowledge. Journal of Language, Identity and Education, 1(4), 243-259.

Eraut, M. (2007). Learning from other people in the workplace. Oxford Review of Education, 33(4), 403-42.

Gherardi, S. (2001). From organizational learning to practice-based knowing, Human Relations, 54 (1), $131-9$.

Gherardi, S. (2009). Commuinty of practice or practices of a community? In S. Armstrong \& C.Fukami (Eds.), Sage handbook of management learning, education and development. (pp. 514530). London UK: Sage Publications.

Gherardi, S. (2013). How to conduct a practice-based study: Problems and methods. Cheltenham, UK, Edward Elgar.

Giddens, A. (1984). The constitution of society: Outline of the theory of structuration. Berekley, CA: Univeristy of California Press. 
Kemmis, S., \& P. Grootenboer (2008). Situation praxis in practice. In S.Kemmis., \& T.J.Smtih, Enabling praxis: Challenges for education (pp. 37-62) . Rotterdam, Netherlands: Sense Publications.

Lave, J., \& Wenger, E. (1991). Situated learning. Legitimate perhipheral participation, Cambridge, MA : Cambridge University Press.

Lloyd, A. (2010). Framing information literacy as information practice: site ontology and practice theory. Journal of Documentation, 66(2), 245-258.

Lloyd, A (2011). Trapped between a rock and hard place: What counts as information literacy in the workplace and how is it conceptualized. Library Trends, 60(2), 277-296.

Lloyd, A. (2012). Information literacy as a socially enacted practice: Sensitising themes for an emerging perspective of people-in-practice. Journal of Documentation, 68(6), 772-783.

McKenzie, P. (2002). A model of information practices in accounts of everyday-life information seeking. Journal of Documentation, 59(1), 19-40.

Nicolini, D. (2009). Articulating and writing practice through the interview to the dobule. Management Learning, 40(2), 195-212.

Orlikowski, W., J. (2002). Knowing in practice: Enacting a collective capability in distributed organizing. Organization Science, 13 (3), 249-273.

Østerlund, C., \& Carlile. P. (2005). Relations in practice: Sorting through practice theories on knowledge sharing in complex organizations. Information Society, 21(2), pp. 91-107.

Savolainen, R. (2008). Everyday information practice: A social phenomenological perspective.

Maryland, US: Scarecrow Press.

Schatzki, T. (1996). Social practices: A Wittgensteinian approach to human activity and the social. Cambridge, UK; Cambridge University Press.

Schatzki, T. (2002). The site of the social: A philosophical account of the constitution of social life and change., Pennsylvania, University Park PA: Pennsylvania State University Press.

Suchman, L. (1987). Plans and situated action: The problem of human-machine communication, Cambridge: Cambridge University Press. 
Talja, S. (2005). The domain analytic approach to scholar's information pratices. In K. E. Fisher, S. Erdelez, \& L. McKechnie, (Eds.), Theories of information behaviour (pp123-127), Metford, N.J: Information Today.

Talja, S.,\& Hansen, P. (2006). Information sharing. In A. Spink, \& C. Cole. New directions in human information behavior (pp.113-134), Dordrecht, Netherlands: Springer.

Yanow, D. (2004). Translating local knowledge at organizational peripheries, British Journal of Management, 15, (1) 9-25. 